\title{
The Effect of Transformational Leadership on Team Satisfaction: The Mediating Effect of Psychological Safety
}

\author{
Winarto \\ Department of Management \\ Faculty of Economics \\ The University of Methodist Indonesia \\ Medan, Indonesia \\ winarto.zip@gmail.com
}

\begin{abstract}
Following hitherto published research on the positive outcomes of transformational leadership; I hypothesize that transformational leadership leads to higher team satisfaction. However, as suggested by Bass (1999), the mechanisms underlying the relationships between transformational leadership and the outcomes are still worthy of further examination. Thus, in this research, I tested psychological safety as mediating variables on the relationship between team perceptions of supervisors' transformational leadership and team satisfaction in the team level analysis. Based on the data from 83 teams mainly working on companies, the research shows that team perceptions of supervisors' transformational leadership is positively related to team satisfaction. In addition, psychological safety mediates the relationship between transformational leadership and team satisfaction. Finally, the implication for future research and managerial are discussed.
\end{abstract}

Keywords- Transformational Leadership; Psychological Safety; Team Satisfaction

\section{INTRODUCTION}

Transformational leadership has become a focus of research and astonishingly popular research topic after it has been introduced more than three decades ago [1]; [2]. The general attention on transformational leadership inquiry seems to result in favorable outcomes on employees' task performance [3]; [1], employees' engagement [4], employees' organizational commitment and job satisfaction [5]. Although the aforementioned positive associations have been demonstrated by past research, the mechanisms underlying the relationships between transformational leadership and task performance are still worthy of further examination [2], [6]. As proposed by [2], "much more explanation is needed about the workings of transformational leadership," particularly on finding mediating mechanisms linking transformational leadership and the work outcomes.

Research direction then particularly focused on the influence of transformational leadership on work outcomes on team level [7], [8], [9]. Similar to the underlying processes how transformational leadership works; further inquiry is needed to reveal the psychological linkages and mechanisms through which the teams are motivated to achieve high level of performance [1], [10]. In other words, those scholars called for future research to examine the mechanism on how transformational leadership works and to find the mediator variables in which facilitate the relationship between transformational leadership and its outcomes on the team level. It is basically because "a variety of different influence processes are involved in transformational leadership" [6]. Thus, facing the challenge and call from previous research, understanding transformational leadership, its processes and its outcomes on the team level might be a potential area for further examination.

This research explored mechanisms and processes in teams that facilitate the relationship between transformational leadership, team performance, and team satisfaction. Previous research has linked transformational leadership with several aspects of team performance and work outcomes [8], [11]. Reference [2] have examined the facilitating role of psychological safety, the belief that engaging in risky behaviors like voice will not lead to personal harm, on the relationship between transformational leadership and employee voice. However, the outcomes of transformational leadership, particularly on team performance and team satisfaction is still missing and waiting for further investigation. Thus, one question that needs to be asked, however, is whether psychological safety facilitates the link between transformational leadership and team performance.

Drawing from that reasoning, the aims of this paper is to examine whether psychological safety facilitates the linkage of transformational leadership and team performance in team level. Thus, the research question for the present study is, "Does psychological safety mediate the relationship between transformational leadership, team performance, and team satisfaction? I began by reviewing existing finding and theory relevant to the relationship between transformational leadership on team performance and followed by developing research hypothesis. After explaining the research method issue, I presented the result section and then the discussion of the 
study. Finally, research limitation, theoretical and managerial implication are also discussed.

\section{LITERATURE REVIEW}

\section{A. Transformational Leadership and the Favorable Outcomes}

When leaders move the follower beyond immediate selfinterests through idealized influence (charisma), inspiration, intellectual stimulation, or individualized consideration, they are called transformational leadership [2]. The essential focus of transformational leader is that the leader transforms the norms and values of the employees through motivate the employees to perform beyond their own expectations, enhance the employees' involvement with the organization goals and inspire the employees to the vision of leaders [11]. Then, following that ideas, leadership literature has established four components of the leader behavior in transformational leadership [6], [2], [4], [7]:

1. Inspirational motivation (the communication of an appealing vision of the future and the use of symbols to articulate this vision)

2. Idealized influence (behaviors like showing that benefits of the group are more important than benefits of the individual, demonstrating high ethical norms, and being a role model for the subordinates),

3. Individual consideration (coaching, supporting and stimulating subordinates) and

4. Intellectual stimulation (the leader challenges the subordinate to see problems from a different perspective).

Transformational leadership has been an astonishingly popular research topic during the past decades. Leadership researchers in recent years have accumulated a large body of evidence in support of transformational leadership and the outcomes of that leadership style. Further, [13] explained that transformational leadership behavior has positive relationships with follower job satisfaction, follower leader satisfaction, follower motivation, leader job performance, group or organization performance, and rated leader effectiveness. Other outcomes of transformational leadership are employees will be more engaged in their work [4] and they will have high organizational commitment and job satisfaction [5]. Finally, transformational leadership is associated with employee voice [12] and learning culture [14].

The role of leaders in organization's team-based structure is essential. They are required to lead and motivate both individuals and the team as a whole [15]. Prior empirical research showed that transformational leadership is closely related to positive outcome on the team performance [9], [11]. In addition, a meta-analytic also suggested that transformational leadership contributes to high team performance, and team satisfaction [16]. Thus, I arrive with two hypotheses below:

Hypothesis 1: Team perceptions of supervisors' transformational leadership are positively related to team satisfaction.

\section{B. Psychological safety as a Mediating Variable}

Team psychological safety means as a shared belief that the team is safe for interpersonal risk taking [17]. In team level, team member must have similar perception about the psychological safety and it must be characterized by overall team members instead of individual members. Furthermore, reference [12] defined psychological safety as the belief that engaging in risky behaviors like voice will not lead to personal harm. Their paper assumed that employees estimate perceived costs prior to speaking up. For instance, employees who feel significant risks and losses are likely to be silent. Ultimately, as suggested by [18], the performance of an employee might be associated with the willingess to speak up.

This concept also is linked to intragroup safety which means as a nonthreatening psychological atmosphere within a team in which enhance the team members to express and convey their new ideas and foster communication within team members since there is no negative judgment by other team members [19], [20]. In addition, ref [17] suggested that psychological safety enhances team learning because team members are encouraged to discuss errors, seek feedback and information from others. This process is essential in team process that leads to a higher level of team outcomes [21], for instance team performance and team satisfaction.

This research assumes that transformational leadership leads to high team satisfaction, in line with the previous findings. Transformational leaders provide intellectual stimulation and individual consideration which open the team members to express their ideas. Therefore, through this processes, team members could enhance their task-related performance as well as satisfaction. Thus, I come up with a set of hypothesis:

Hypothesis 2a: Team perceptions of supervisors' transformational leadership are related to psychological safety in a team.

Hypothesis 2b: Psychological safety in a team is related to team satisfaction.

Hypothesis 2c: Psychological safety in a team mediates the positive relationship between team perceptions of supervisors' transformational leadership and team satisfaction.

\section{Research Model}

Based on the explanation above, I drew the research model in which explains the main relationship between transformational leadership and its outcomes; team performance and team satisfaction; with psychological safety as mediating variable. The research model is depicted in Figure 1 below.

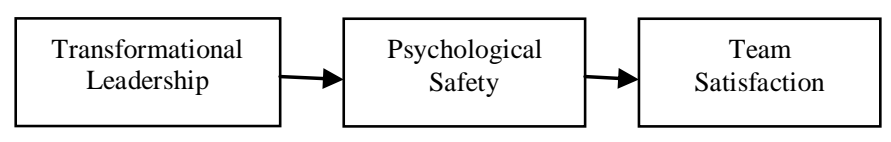

Figure 1 the Research Model 


\section{RESEARCH METHODOLOGY}

This part explains about the research methodology which had been used for the research.

\section{A. Participants and Procedures}

The study was undertaken across 83 teams in different companies. Respondents comprised of 583 employees. Fifty five

percent of team members were men and $45 \%$ were women; with in average they were 39 years old and they have been working in the organization (tenure) for 118 months. Further, they were asked to fill out a set of questionnaires. Data were collected using anonymous self-report questionnaires. Team members were asked to answer 3 constructs; transformational leadership, psychological safety and team satisfaction

\section{B. Measures}

Participants are required to answer the scale measuring the extent to which the statements corresponded to their perception on transformational leadership on the team. This scale has been adapted from [22] with a 7-point Likert-type scale (from 1, 'strongly disagree,' to 7, 'strongly agree') and consisted of 22 statements. Following are sample items from the transformational leadership scale: "always looking for new opportunities," "my leader is a good role model for me," and "my leader develops team spirit among the team members."

To measure psychological safety, the scale from [17] will be used. This scale consists of 7 items with a seven-point scale, ranging from 'strongly disagree' to 'strongly agree.' Participants are required to indicate the degree to which they possess confidence in their skills and abilities. Sample items from this scale include: "Nobody in this team would deliberately undermine my efforts" and "It is not difficult to tell other members of the team to ask for help."

Job satisfaction was measured by using the following fouritem scale: I enjoy my work, my job does not make me bored, I am very satisfied with my work, I would like to continue to do this work

\section{Aggregations and Testing Hypothesis}

The level of analysis in this research is in team level. Therefore, the level analysis of the scale and the data must be at the same. The transformational leadership items, psychological safety scales, and team satisfaction are based on individual level. Therefore, these items were aggregated to create a single score in team level analysis.

I used stepwise regression and followed Baron and Kenny's procedure [23] for testing the research hypotheses to examine the mediating role of psychological safety in the transformational leadership and team satisfaction relationship. To enhance the mediation process, I also followed Sobel test and bootstrap.

\section{RESULTS}

Table 1 presents the means, standard deviations, coefficient alphas, and correlations of all variables investigated in this study.

\begin{tabular}{|c|c|c|c|c|c|c|c|}
\hline Variables & Alpha & Mean & SD & 1 & 2 & 3 & 4 \\
\hline 1. Age & & 38.16 & 8.26 & - & - & - & - \\
\hline 2. Tenure (months) & & 113.60 & 74.87 & $0.74 *$ & - & - & - \\
\hline $\begin{array}{l}\text { 3.Transformational } \\
\text { leadership }\end{array}$ & 0.93 & 4.83 & 0.57 & -0.16 & $-0.24 * *$ & - & - \\
\hline $\begin{array}{l}\text { 4. Psychological } \\
\text { safety }\end{array}$ & 0.76 & 5.27 & 0.47 & -0.14 & -0.14 & $0.42 *$ & - \\
\hline 5. Team satisfaction & 0.90 & 5.51 & 0.61 & $0.20 * * *$ & 0.10 & $0.32 *$ & $0.39 *$ \\
\hline
\end{tabular}

The correlations between variables were described in Table 1. Then, Cronbach Alpha was used to assess the internal consistency/reliability of each construct. Values of Alpha ranged from 0.76 to 0.93 , and thus exceeded Nunnally's recommended cut-off of 0.7. Transformational leadership correlated positively with psychological safety $(r=0.42, p<$ $0.01)$, and team satisfaction $(\mathrm{r}=0.32, \mathrm{p}<0.01)$. Additionally, psychological safety correlated positively with team satisfaction $(r=0.39, p<0.01)$. Moreover, age as one of the control variables has negative correlation with psychological safety, but the relationship was not statistically significant $(\mathrm{r}=$ $0.14, p>0.1)$ and positive relationship with team satisfaction ( $r$ $=0.20, p<0.1)$. Finally, tenure was not related to team satisfaction $(\mathrm{r}=0.1, \mathrm{p}>0.1)$. I included age as the control variable in the regression analyses which were expected would affect the results and excluded tenure from the analysis because it was not related to dependent variable.

Table 2 summarizes the regression analysis to test the relationship between transformational leadership, psychological safety, team satisfaction. Hypothesis 1 postulated that transformational leadership would be positively related to team satisfaction. The regression analysis showed that transformational leadership was related to team satisfaction $(\beta=0.34, p<0.01)$. Therefore, hypothesis 1 was supported.

Table 2 Regression summary for the relationship between transformational leadership and team satisfaction

\begin{tabular}{lcc}
\hline & leadership and team satisfaction & \\
Age & Psychological Safety & Team Satisfaction \\
$\mathrm{R}^{2}$ & -0.01 & $0.02^{* * *}$ \\
\hline \hline Transformational & 0.02 & 0.04 \\
Leadership & $0.35^{*}$ & $0.34^{*}$ \\
$\mathrm{R}^{2}$ & 0.18 & 0.10 \\
\hline \hline Psychological Safety & - & $0.50^{*}$ \\
$\mathrm{R}^{2}$ & - & 0.15 \\
\hline
\end{tabular}

*. Correlation is significant at the 0.01 level (2-tailed)

**. Correlation is significant at the 0.05 level (2-tailed)

***. Correlation is significant at the 0.1 level (2-tailed)

Hypothesis 2a expected that team perceptions of supervisors' transformational leadership are related to 
psychological safety in a team. The regression analysis showed that hypothesis $2 \mathrm{a}$ was supported $(\beta=0.35, \mathrm{p}<0.01)$. Thus, transformational leadership has positive relationship with psychological safety. Moreover, Hypothesis $2 \mathrm{~b}$ postulated that psychological safety in a team is related to team satisfaction. The regression analysis showed that the hypothesis was supported $(\beta=0.50, \mathrm{p}<0.10)$.

Following the analysis above, I conducted mediating analysis by using Sobel test and bootstrap (Preacher \& Hayes, 2004; Hayes 2007).

Table 3 presents the Sobel test and bootstrap 95\% confidence interval. Hypothesis $2 \mathrm{c}$ expected that psychological safety mediates the relationship between transformational leadership and team satisfaction. The Sobel test showed that psychological safety significantly mediated the link between transformational leadership and team satisfaction (value = $0.1435, \mathrm{z}=2.3022, \mathrm{p}<0.05)$. The Lower Limit (LL) was 0.0213 and the Upper Limit (UL) was 0.2653. In this case, the indirect effect is $95 \%$ likely to range from 0.0213 to 0.2653 , thus the estimated effect is 0.1435 was lying in between these two values. Therefore, it can be concluded that the indirect effect is significant, or psychology safety significantly mediates the relationship between transformational leadership and team satisfaction. Thus, hypothesis $2 \mathrm{c}$ was supported.

Table 3 The Mediating Effect

Effect psychological safety on the relationship between transformational leadership and team satisfaction

\begin{tabular}{cc}
\hline Value & 0.1435 \\
SE & 0.0623 \\
LL 95 CI & 0.0213 \\
UL 95 CI & 0.2653 \\
Z & 2.3022 \\
Sig (2-tailed) & 0.213 \\
\hline
\end{tabular}

\section{CONCLUSION AND IMPLICATIONS}

The aim of the research is to investigate the mediating role of psychological safety in the relationship between transformational leadership style and team satisfaction. While previous studies focused on an individual level analysis, this research was conducted in a team level.

This statistic results of the research confirm the previous' findings. Hypothesis 1 was supported, thus team perceptions of supervisors' transformational leadership are related to team satisfaction. This means that leaders who engage in transformational leadership behavior would lead positive outcomes. Followes of transformational leaders should be more satisfied with the leaders [2] [13]. Ref [26] argue that transformational leaders involve motivating others which lead to the followers to be more satisfied.

Hypothesis 2a expected that transformational leadership style is related to psychological safety, whereas Hypothesis $2 \mathrm{~b}$ predicted that psychological safety is related to team satisfaction. Both of them are supported by the data and statistical analysis. One of the transformational leadership dimensions is related to intellectual stimulation where the leaders challenge the followers to see and think problems from a different perspective. They should think out of the box. Consequently, as a transformational leader, he/she should ensure the followers that their thoughts, voices and solutions will not lead to personal harm [12] [17]. The transformational leader should open his/her mind and be ready with any followers' thoughts.

From the followers' perspective, followers evaluate perceived costs before giving their voices and speaking up [12]. When they perceived that the transformational leaders warrant the followers to speak up, they are likely to giving his/her thoughts. They feel that expressing and conveying their ideas and thoughts are guaranteed by the transformational leaders and there is no negative judgment by other team members [19] [20]. This mechanism is beneficial for team process and team outcomes, in particular, the followers are likely to be more satisfied.

The Hypothesis 2c was supported. The result of the Sobel test and bootstrap $95 \%$ confidence interval shows that psychological safety mediates the relationship between transformational leadership and team satisfaction. This means that transformational leadership has direct and indirect effect on team satisfaction via psychological safety.

The findings contribute to the literature with regards to the underlying process on how transformational leadership style influence team satisfaction. Theoretically, when transformational leaders offer an atmosphere where the followers feel safe to express their thoughts and ideas, this process leads the followers to be more satisfied. Practically, to improve team satisfaction within organization, it is suggested for leaders to display transformational leadership behavior. The leaders then should give the followers to freely express their thought and ideas, and guarantee that followers' voices will not be harmful. Ultimately, the followers are more likely to be satisfied.

This research has limitations. Firstly, the number of teams used for the analysis was relatively small, whereas Sobel test and bootstrap need a high number of unit analysis. Thus, future research must take in to account the number of teams by adding the number of the team. Secondly, this research did not make any differentiation of business scale or type. Therefore, future research needs to consider the following aspects such as company scale, company age, and business type as control variables.Thirdly, future research may use psychological safety as a moderator variable to see the condition (low or high psychological safety) in which strengthen or weaken the relationship between transformational leadership and team satisfaction.

\section{REFERENCES}

[1] Aryee, S., Walumbwa, F. O., Zhou, Q., \& Hartnell, C. A. (2012). Transformational leadership, innovative behavior, and task performance: Test of mediation and moderation processes. Human Performance, 25, $1-25$.

[2] Bass, B. M. (1999). Two decades of research and development in transformational leadership. European Journal of Work and Organization Psychology, 8(1), 9-32.

[3] Tsai, W.-C., Chen, H.-W., \& Cheng, J.-W. (2009). Employee positive moods as a mediator linking transformational leadership and employee 
work outcomes. The International Journal of Human Resource Management, 20(1), 206-219.

[4] Tims, M., Bakker, A. B., \& Xanthopoulou, D. (2011). Do transformational leaders enhance their followers' daily work engagement? The Leadership Quarterly, 22, 121-131.

[5] Walumbwa, F. O., Lawler, J. J., Avolio, B. J., Wang, P., \& Shi, K. (2005). Transformational leadership and work-related attitudes: The moderating effects of collective and self-efficacy across cultures. Journal of Leadership \& Organizational Studies, 11(3), 2-16.

[6] Yukl, G. (2012). Leadership in Organizations (Vol. 8th). Pearson Higher Ed USA.

[7] Braun, S., Peus, C., Weisweiler, S., \& Frey, D. (2013). Transformational leadership, job satisfaction, and team performance: A multilevel mediation model of trust. The Leadership Quarterly, 24, 270-283.

[8] Dionne, S. D., Yammarino, F. J., Atwater, L. E., \& Spangler, W. D. (2004). Transformational leadership and team performance. Journal of Organizational Change Management, 17(2), 177-193.

[9] Bass, B. M., Avolio, B. J., Jung, D. I., \& Berson, Y. (2003). Predicting unit performance by assessing transformational and transactional leadership. Journal of Applied Psychology, 88(2), 207-218.

[10] Avolio, B. J., Walumbwa, F. O., \& Weber, T. J. (2009). Leadership: Current theories, research, and the future directions. Annual Review of Psychology, 60, 421-449.

[11] Schaubroeck, J., Lam, S. S., \& Cha, S. È. (2007). Embracing transformational leadership: Team values and the impact of leader behavior on team performance. Journal of Applied Psychology, 92(4), 1020-1030.

[12] Detert, J. R., \& Burris, E. R. (2007). Leadership behavior and employee voice: Is the door really open? Academy of Management Journal, 50(4), 869-884.

[13] Judge, T. A., \& Piccolo, R. F. (2004). Transformational and transactional leadership: A meta-analytic test of their relative validity. Journal of Applied Psychology, 89(5), 755-768.

[14] Nemanich, L. A., \& Vera, D. (2009). Transformational leadership and ambidexterity in the context of an acquisition. The Leadership Quarterly, 20, 19-33.

[15] Chen, G., Kirkman, B. L., Kanfer, R., \& Allen, D. (2007). Multilevel study of leadership, empowerment, and performance in teams. Journal of Applied Psychology, 92(2), 331-346.

[16] Wang, G., Oh, I.-S., Courtright, S. H., \& Colbert, A. E. (2011). Transformational Leadership and performance across criteria levels: A meta-analytic review of 25 years of research. Group \& Organization Management, 36(2), 223-270.

[17] Edmondson, A. (1999). Psychological safety and learning behavior in work teams. Administrative Science Quarterly, 44, 350-383.

[18] Ashford, S. J., Rothbard, N. P., Piderit, S. K., \& Dutton, J. E. (1998). Out on a limb: The role of context and impression management in selling gender-equity issues. Administrative Science Quarterly, 43, 2357.

[19] Hulsheger, U. R., Anderson, N., \& Salgado, J. F. (2009). Team-level predictors of innovation at work: A comprehensive meta-analysis spanning three decades of research. Journal of Applied Psychology, 94(5), 1128-1145.

[20] Kahn, W. A. (1990). Psychological conditions of personal engagement and disengagement at work. Academy of Management Journal , 33(4), 692-724.

[21] Kessel, M., Kratzer, J., \& Schultz, C. (2012). Psychological safety, knowledge sharing, and creative performance in healthcare teams. Creativity and Innovation Management, 21(2), 147-157.

[22] Podsakoff, P. M., Mackenzie, S. B., Moorman, R. H., \& Fetter, R. (1990). Transformational leader behaviors and their effects on followers' trust in leader, satisfaction, and organizational citizenship behavior. Leadership Quarterly, 1(2), 107-142.

[23] Baron, R. M., \& Kenny, D. A. (1986). The moderator-mediator variable distinction in social psychological research: Conceptual, strategic, and statistical considerations. Journal of personality and social psychology, $51(6), 1173$
[24] Preacher, K. J., \& Hayes, A. F. (2004). SPSS and SAS procedures for estimating indirect effects in simple mediation models. Behavior research methods, 36(4), 717-731.

[25] Preacher, K. J., Rucker, D. D., \& Hayes, A. F. (2007). Addressing moderated mediation hypotheses: Theory, methods, and prescriptions. Multivariate behavioral research, 42(1), 185-227.

[26] Avolio, B. J. (1999). Full leadership development. Thousand Oaks, CA: Sage. 